\title{
7 Converting and Extending a Historic Fire Station into a Library in Berlin, Germany
}

\begin{abstract}
The new central library in Treptow, Berlin, Germany is located in a listed, early $20^{\text {th }}$ century fire station which had been in a state of neglect for many years. The building is in a historic area and is surrounded by other important listed buildings including a waterworks building and a school. The renovation and extension of the building provided the district with an exciting and well-located new library and restored a landmark building to its former glory. The project was challenging in many ways not least because of the importance of maintaining the integrity of the original building, which has several constituent parts, while ensuring that it worked with the new extension to form a cohesive new complex which functioned well as a library. Materials for the extension were selected with care to complement the old, particularly in addressing the new roofscape as a whole. The crux of the project was to retain a building which is a symbol of the past, but which also creates a new contemporary library.

The library is on three levels and the new extension connects to the historic building on the ground and first floors. The library is welcoming with a spacious entrance and a central information and service counter with a good overview of the whole space. In addition, the library is barrier-free, flooded with natural light and able to be used for events outside normal opening hours. The competition brief included specific requirements from the library staff which have been successfully met in the final design despite all the challenges posed.
\end{abstract}

Keywords: Library buildings; Public libraries - Germany; Fire stations - Remodelling for other use

\section{Introduction}

The historic town of Köpenick has been a protected area in Berlin since 1993. In Berlin's 2001 administrative reform, the borough of Köpenick was merged with Treptow to create the borough of Treptow-Köpenick. In 2007, Köpenick was designated as a redevelopment area, which included three new library projects. The three-part building programme was to be developed by renovating and converting two existing historic protected buildings and by constructing a new building for the public area.

2 Open Access. (22021 Robert Niess and Jürgen Radzkowski, published by De Gruyter. (c) BY-NC-ND This work is licensed under the Creative Commons Attribution-NonCommercial-NoDerivatives 4.0 International License. 


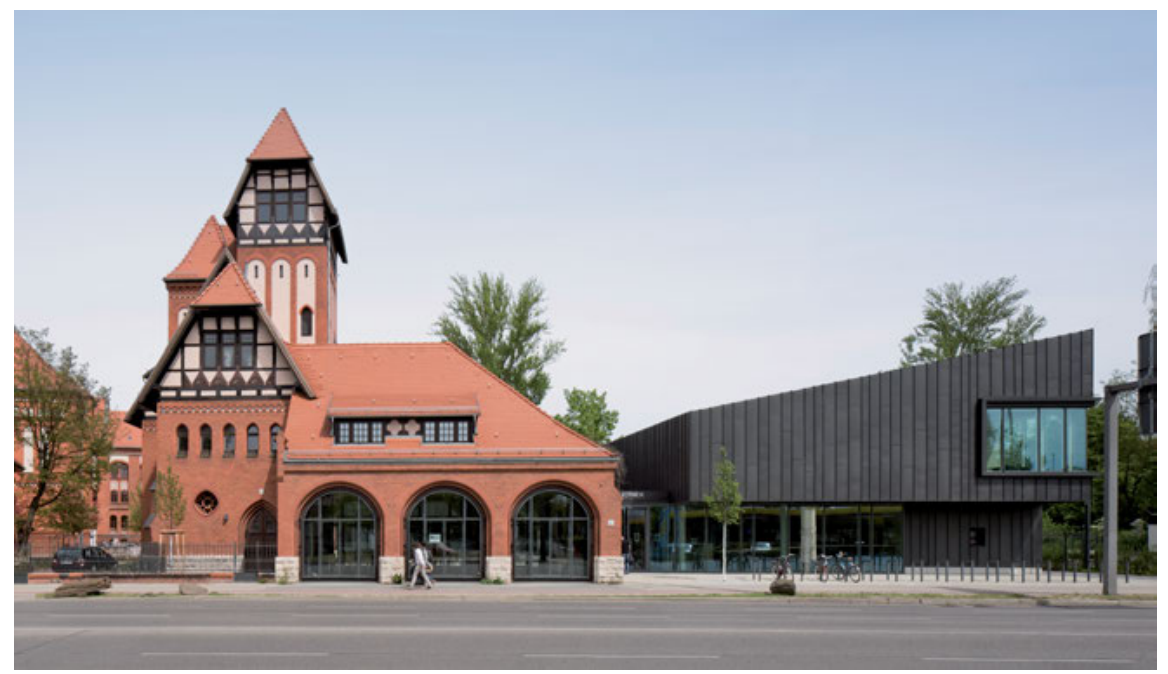

Fig. 1: The finished project 2015. (@) Werner Huthmacher.

\section{Facts and Figures}

Name: Mittelpunktbibliothek Treptow Alte Feuerwache

Address: Michael-Brückner-Straße 9, 12439 Berlin, Germany

Website: https://www.voebb.de/aDISWeb/app?service=direct/0/

Home/\$DirectLink\&sp=SPROD11\&sp=Sis 1459

Opening: April 2015

Builder: Bezirksamt Treptow-Köpenick von Berlin

Architects: Chestnutt_Niess Architekten BDA http://www.chestnutt-niess.de/

Gross floor area: $2,050 \mathrm{~m}^{2}$

Main floor space: $1,500 \mathrm{~m}^{2}$

Collection size: 75,000

Staff: 15

Workstations: 35

Building costs: $€ 6,400,000$

The first library design in the old town was realised in 2007/2008. The new library merged four district libraries, including their offices, with the storage area for the mobile library as well as two library administration sites. It was a success and created a positive mood that led to the planning and construction of the second library project in Treptow focusing on the Alte Feuerwache/Old Fire Station. 


\section{The Background}

Treptow-Köpenick, at $168 \mathrm{~km}^{2}$, is the largest district of Berlin and is located in the southeast of the city. Just over half of the district's area is made up of forest and water, which is equivalent to the area of downtown Berlin. The approximately 274,000 inhabitants (as of 2019) are spread across 15 localities, which are assigned to five district regions as city-wide planning areas. The social structure is characterised by a positive social index, high average age, low share of foreign nationals and citizens with a migration background, medium level of education, medium average income and low unemployment. Instead of a district centre, Treptow-Köpenick has only regional and local residential areas, which are often separated by forest and water.

The former library system used to reflect the locality structure, and in 2007 comprised 14 locations and a mobile library but no main library. This multi-library landscape was unique in Berlin. Limited service and a lack of demand caused a sharp decline in visits, lending transactions and participation in events. As a result, funds and staff were continually cut over the years. Berlin's budgetary difficulties since 2000 contributed further to the downward spiral. After much consideration, it was clear that a Stadtbibliothek/City Library as a recognisable urban entity and an exciting place was needed.

To consolidate the financial situation and realign the library system, changes including new objectives, were considered necessary by the district and the library. The creation of a structured plan was agreed upon, which would be evaluated and updated regularly within a specified timeframe. Strategic goals included the reduction of the number of libraries by merging several at new locations, combining resources, optimising work processes, innovative methods for promoting reading and information literacy, investment planning at the district and city-wide level for library buildings, introduction of RFID technology, digital media offers and individual projects relating to targeted needs.

\section{The Long Journey to Finding the Right Location}

With the decision to locate Treptow's new Mittelpunktbibliothek/Central Library in the Alte Feuerwache/Old Fire Station in the area called Niederschöneweide, an attractive but also challenging location was finally found. Niederschöneweide is located near the south bank of the river Spree, approximately in the centre of the old district of Treptow. Bus, tram, urban and regional railways form a highly frequented public transport hub. Road traffic is concentrated on the busy federal 
road 96a, which crosses the district in a north-south direction and connects the City East with the new Berlin Brandenburg Airport (BER).

The surrounding area is formed by four districts on an area of $22 \mathrm{~km}^{2}$ with around 75,000 residents. It corresponds to the social structure of the entire district, with the locality Oberschöneweide, just across the river on the north side of the Spree as the only exception. University centres, start-ups and creative industries in the region result in a significantly younger average age among the population and a higher preponderance of foreign nationals and citizens with a migration background.

The entire catchment area used to have four libraries spread out in five buildings. All buildings were in remote locations. The available rooms were unsuitable for media presentations, on-site use, appropriate library operations and events, and were simply unattractive. The shortcomings could be remedied by merging the multiple locations on one new site in an attractive building. The responsible local authorities proposed an extension and reuse of the former town hall of Johannisthal, built in 1904/1905. The selected property had considerable disadvantages for the new library building because of its location on the outskirts of the district and poor access to public and private transportation.

Weighing the advantages and disadvantages very quickly demonstrated that an alternative location had to be found. The new selection was limited by the requirement that both property purchase and rental should be excluded for financial reasons. Therefore, the search was limited to properties and buildings in public ownership. The potential locations were either vacant buildings or buildings temporarily rented for external or non-public use. A suitable location was finally found with the former fire station, Alte Feuerwache (Figure 2), located since the beginning of the $20^{\text {th }}$ century in an urban area which had been undergoing redevelopment since 1994. As of 2010, the planning for the construction project could begin in earnest with the transfer of the property from the general financial assets to the specialist assets of the Stadtbibliothek Treptow-Köpenick.

\section{Finally - the Reuse of the Heritage Listed Old Fire Station}

The fire station had been originally built in 1908 for a rural but rapidly growing community and had shaped the cityscape of the district. In the following decades, the volunteer and professional fire brigade and later the traffic police were based in the building. The structure suffered only minor damage in the second World War. The fire station was in use for much of the period of the German Democratic 
Republic (GDR) from 1949 to 1990 but suffered long-term damage from improper construction work facelifting the elevation facing the street. From 1990 onwards, after the fall of the Berlin Wall, usage alternated from vacancy to various social uses by external associations and groups. The maintenance of the building was simply neglected and for many years left to decay. The interiors were changed significantly and the historic quality of the building suffered much damage through inappropriate and ad-hoc alterations. The Mittelpunktbibliothek Treptow project came at the right time to preserve and restore the listed historic building, which has been protected since 1994.

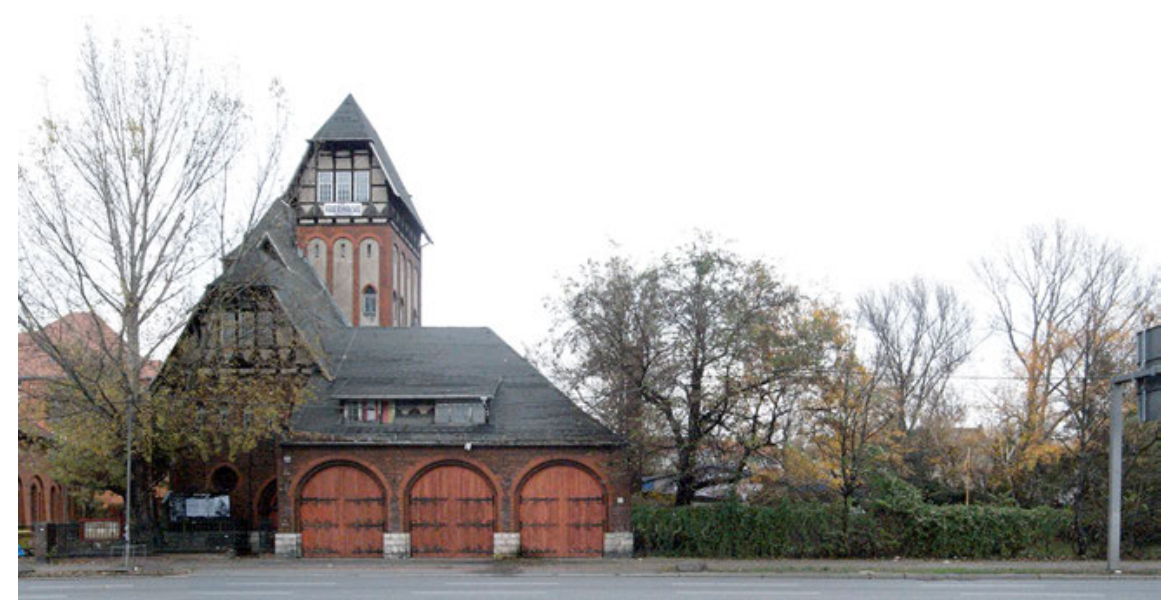

Fig. 2: The Alte Feuerwache/Old Fire Station before restoration ca. 2009. (c) Chestnutt-Niess Architekten.

\section{The Building and its Surroundings}

The original fire station building consisted of several parts: the main building, the carriage hall and the hose tower. Together with the new three-level extension, they form the new library. The Wasserwerk Johannisthal/Waterworks operate a pump station in the immediate neighbourhood. Other neighbouring historic listed buildings are the official's residence (1905), the pump station (1902) and the machine house (1922). They are located behind the library and can be viewed through a large north window. The most prominent neighbours are the elementary and secondary schools, designed by the architect Paul Egeling and built in 1898/1899. Both buildings are listed historic buildings. War damage and lack of building maintenance in East Germany were addressed with limited remedies 
in the 1970s. In 2010, both the school buildings were extensively renovated, and the façades restored. The two-level Gymnasium/Secondary School and the fire station are built side by side on the street front (Figure 3).
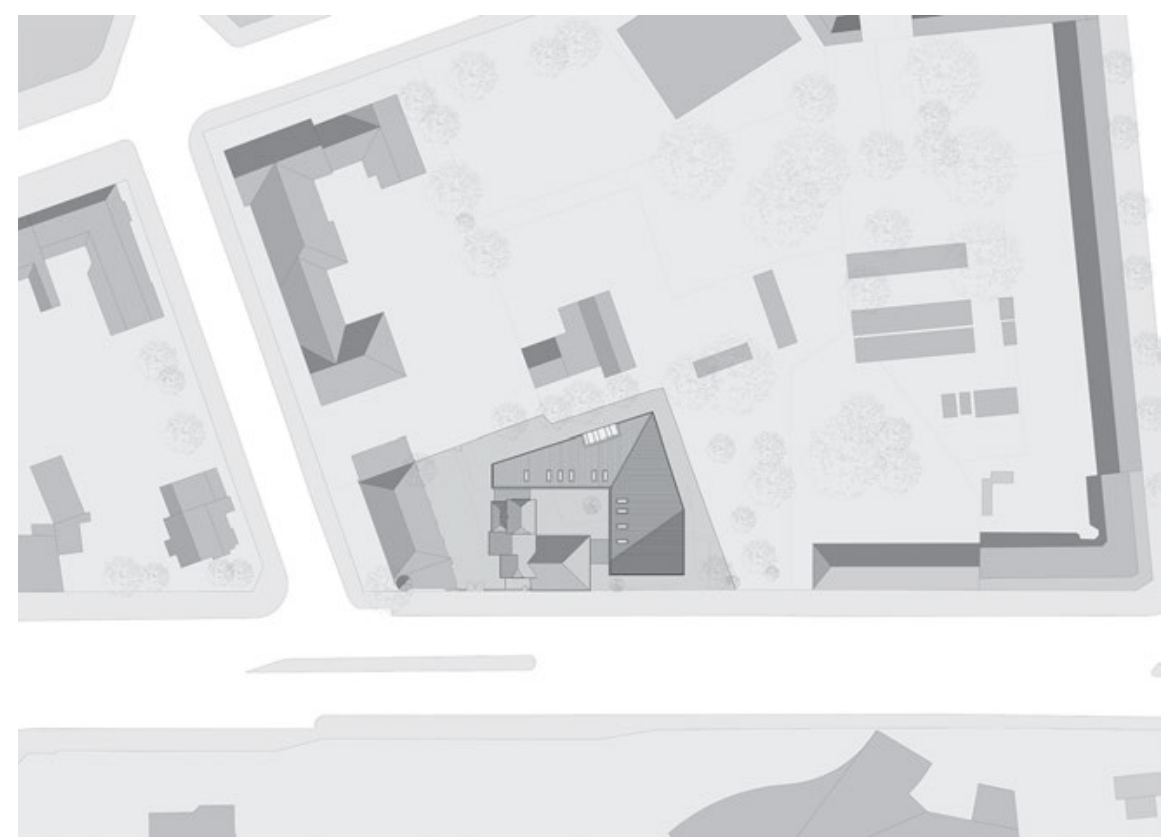

Fig. 3: Site plan of the library. (C) Chestnutt-Niess Architekten.

\section{Notes from the Architects}

\section{The Urban Concept}

The listed historic Fire Station in Treptow, designed and built in 1907/08 by the Architect Karl Alfred Herrmann, is an intriguing and unusual building. Through its architectonic massing and stylistically differently proportioned volumes, the fire station has something distinctive and symbolic about it. It is a curious building typology that consists of a tectonic grouping of individual parts, including the fire engine hall, hose tower and administrative building. Not only are the fragmented parts clearly legible in themselves but they also fit together sculpturally into a singular cohesive design. The building composition brings together different construction methods, materials and decorative elements. The differ- 
ences are demonstrated not only in the use of varying materials such as half-timbering and decorative masonry but also through contradictory building elements such as false bay windows and false balconies. In researching the building, it was discovered that the different constructional situations, forms and elements were designed to serve as simulations for exercise purposes for the firemen. The old building is in a way a functional stage set. One of the main architectural devices in the heterogeneous building is the multitude of roof shapes, which in their entirety create a roof landscape spreading over, and unifying, the entire ensemble.

The urban planning concept for the new extension to the old building focuses on shape, proportion and colour, as well as on function, spatial sequence and construction, with the aim of creating a new building ensemble comprising both old and new. The goal was to include as much of the old building as possible in the spatial experience of the new library and at the same time change as little as possible of the original structure (Figure 4).

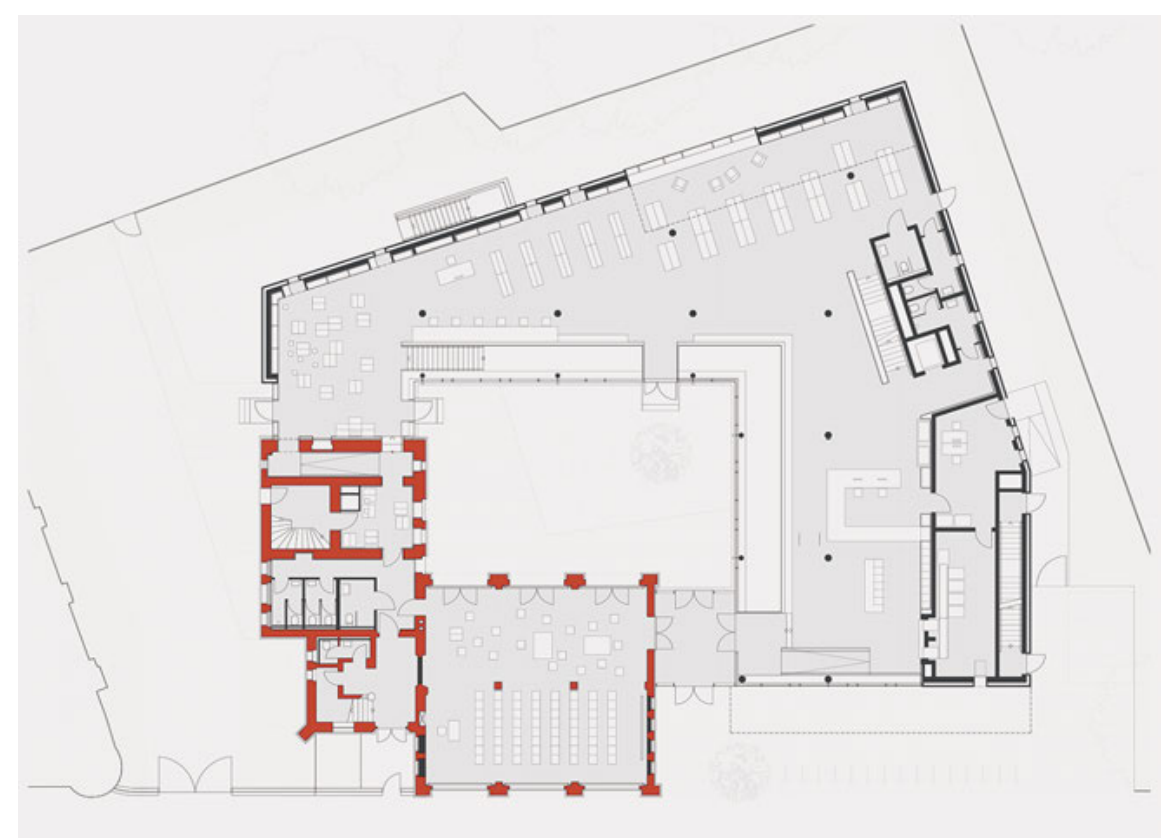

Fig. 4: Ground floor plan of the library with the existing structure shown in red and the extension in black. (c) Chestnutt-Niess Architekten.

The shape of the new building resembles a spiral that uses the former hose-tower of the fire station as its fulcrum (Figure 1). The architectural formulation of the defining roofscape was adopted and reformulated in the new design. The interior 
and the roof shape of the new structure taper or enlarge and wrap around forming a noise-protecting courtyard for outdoor reading. The roof pitch of the new building drops down to the scale of the engine hall of the old building and emphasises both the old building and the courtyard as the centre of the complex. The shape of the spiral largely results from the building height in relation to the property boundary as an optimised shape. The new and old together create an ensemble that reinforces the symbolism of the past and presents itself as a free-standing public building, mysterious and inviting (Figure 5).

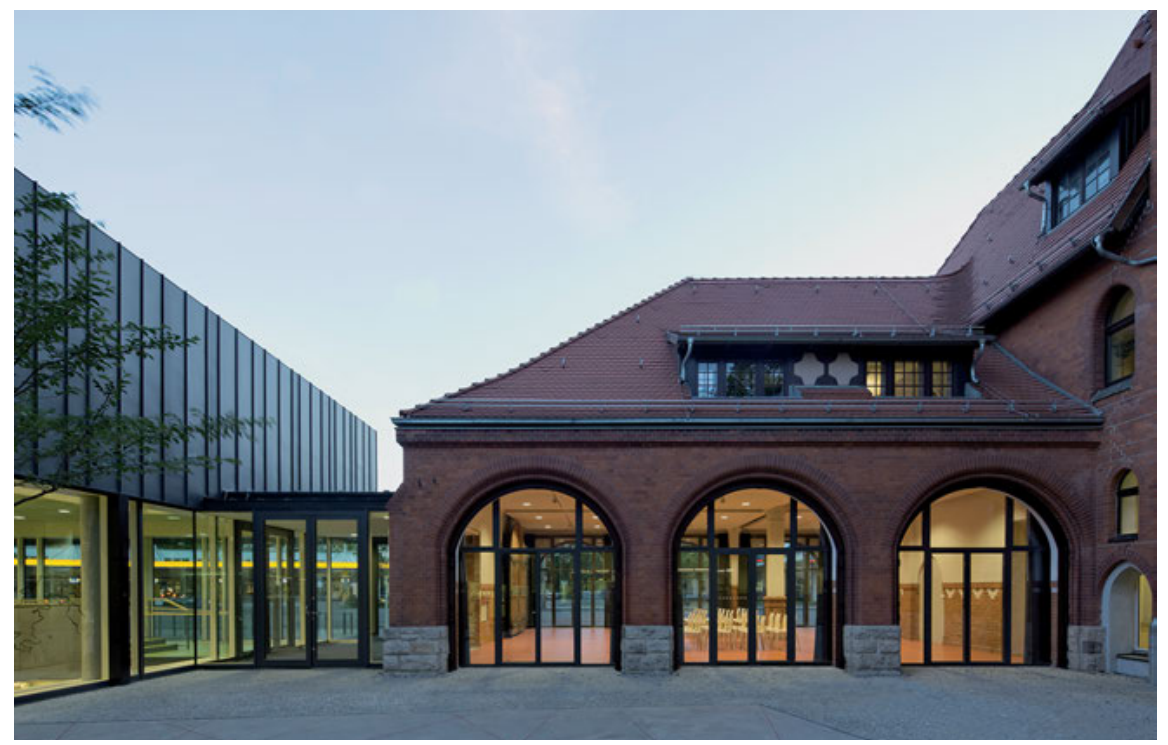

Fig. 5: The library courtyard and old fire engine hall. (c) Werner Huthmacher.

\section{The Architectural Concept of the Library}

The new library has three levels, a subterranean level, a slightly elevated ground level and an upper floor. Large cutouts in the floors and walls structure the spatial flow and create an interplay of views into, through and out of the building. The spatial juxtaposition between levels, between interior and exterior spaces and between new and historic spaces serves to create a connection on the one hand while promoting the uniqueness of different areas on the other. The new extension is connected to the old building on the ground floor and first floor which together with an elevator makes the entire structure fully barrier free and accessible for all users. 
On the ground floor, the new building opens up to the courtyard allowing large amounts of natural light to penetrate into the subterranean level through the voids in the ground floor. In addition to the monastery-like slit windows with

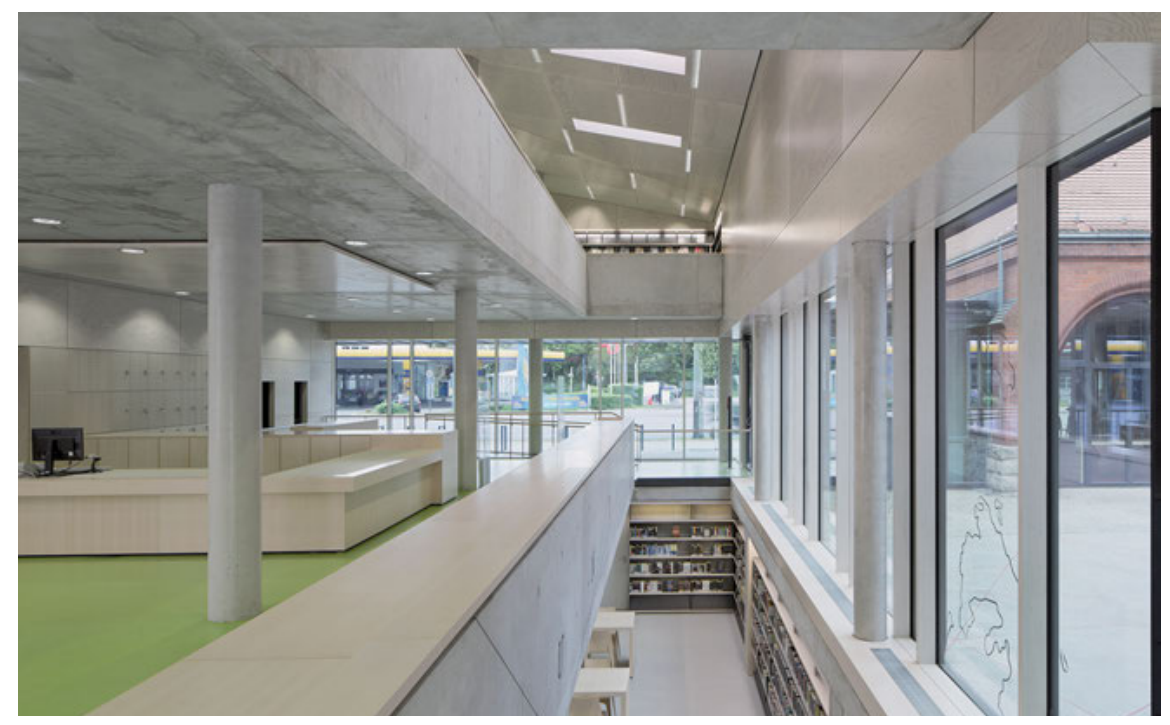

Fig. 6: The entrance area of the library. (@ Werner Huthmacher.

small reading benches, three large windows are positioned on the upper floors in such a way that they allow a selected urban view and, in turn, direct natural light through the voids.

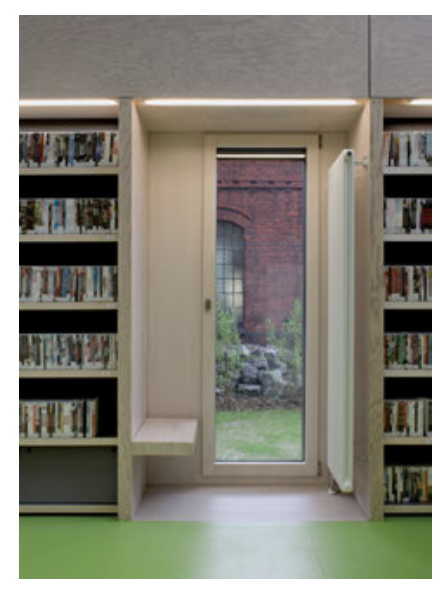

Fig. 7: View of a window seat. (C) Werner Huthmacher. 
The entrance is spacious and easy to find (Figure 6). Bright and friendly the small foyer acts as a distribution area allowing access into the library or the event and seminar room in the former fire engine hall or the courtyard, regardless of the library's opening hours. The former fire engine hall is prominent, emblematic and designed to be used for events self-sufficient of the library. For independent usage, it has its own toilets and chair storage. The courtyard serves as the library's confined exterior space for reading and relaxing outdoors. The courtyard also provides the option to be integrated as an outside area for the event space (Figure 10).

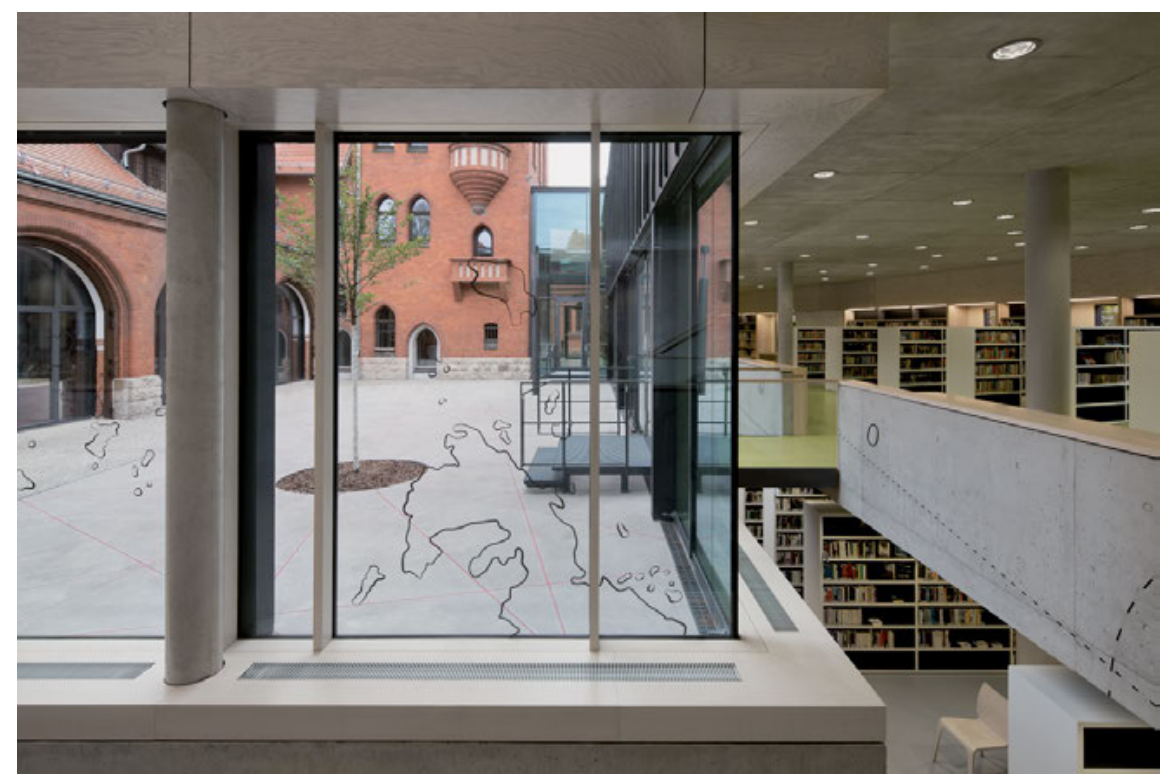

Fig. 8: The library courtyard with the work of art "Imago Mundi" from Ricarda Mieth. @ Werner Huthmacher.

In the library entrance area are lockers, a bench, an exhibition space with information material and an automated book return (Figure 6). For 24/7 book return, an external weather-protected book deposit is located nearby.

The information or service counter is prominently located directly at the entrance beside the security gates. Beyond the gates, an area for self-service lending machines, workstations and printers is provided. A staff back office has direct external access for deliveries and a connection to the automated book return and sorting area and is directly connected with the service counter.

At the service counter, a large opening with natural light from the courtyard enables visitors to see into the upper and lower floors of the new library thus pro- 
viding a good overview and orientation throughout the whole building. Thanks to the spacious and open entrance area, the building offers a resounding welcome to its visitors.

Centrally located and easily visible from all points, a gentle and wide staircase provides for quick and direct access to all levels of the library. In addition to the stairs, an elevator provides access to all levels of the new and the old building. Visitor toilets suitable for those with disabilities are also centrally located here. Additional fire escape stairs are tucked away at the end of each wing.

Past the stairs, the youth and children's area is on the ground floor (Figure 9). The youth area for ages seven to twelve is up front near the service counter. The area for small children up to six is mainly in the rear with some space for children and their parents in the adjoining old building. An information point at the interface between the two areas ensures a good overview. An internal connection between the children's area and the former fire engine hall is possible for special uses. There is a secure outdoor play area on the western side with direct access from the neighbouring elementary school.

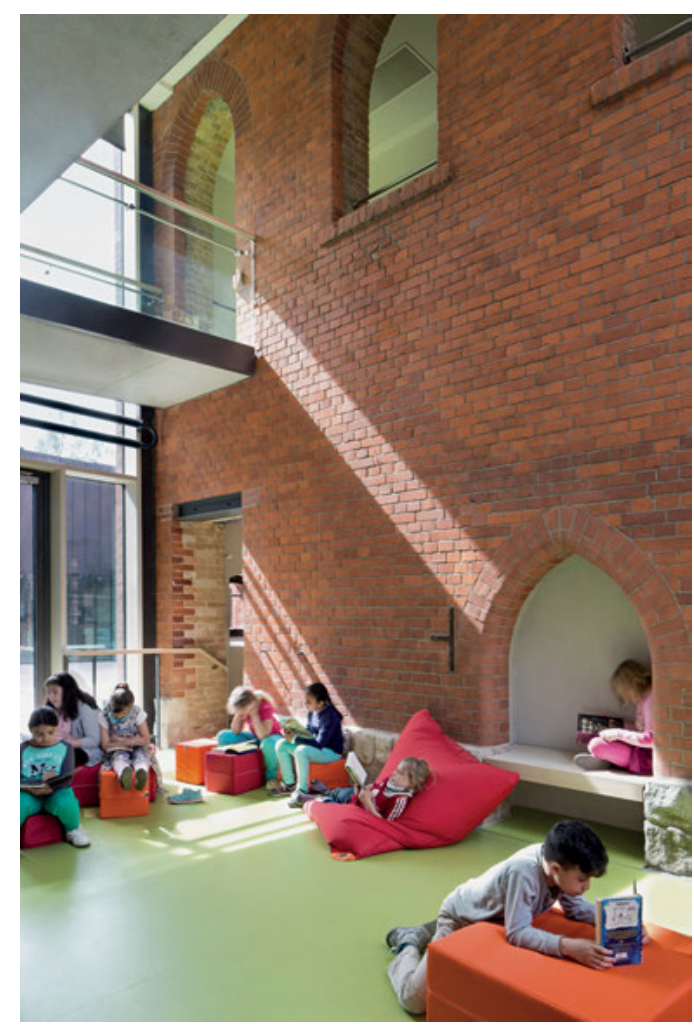

Fig. 9: The children's area of the library. (c) Werner Huthmacher. 
An audiovisual area is located on the lower level, with a student study area in the eastern wing and the non-fiction collection in the southern wing. Reading places are provided throughout. Large openings in the ceiling direct the views to the outside and flood the lower level with natural light while subtly subdividing the areas through the spatial variety.

Magazines and fiction for adults and young adults are provided on the upper floor. A communication area with a coffee bar is located next to the stairs and close to the magazine reading area. In addition to the coffee bar, elevator and toilets, a closed copy/printing room is available. Free standing as well as built-in reading tables on the low walls bordering the voids create attractive spaces for concentrated study and group work (Figure 7).

The library's administration offices are housed in the old building on the upper floor, above the former fire engine hall, and have direct access to the library lending area. In terms of design and construction, all additions were structurally separated from the existing building allowing for as little costly intervention in the existing structure as possible.

In the design of the new ensemble of old and new, it was quickly realised that the selection of materials for the new building was of great importance. The outer skin of the new building picks up on the originally dark patina of the tiled roof and reverses its solidity by the use of anthracite-coloured zinc sheet cladding. Large, glazed openings as cutouts serve as compositional elements of the new building and give the shape a lightness. With the cladding, the massive red brick old building is clearly centrally placed. The same metallic skin covers both the walls and the roof of the extension, creating a physicality that stands in dialogue with the tectonic structure of the old building. While the skin protects the construction of the outer walls like a raincoat, the inside of the new building is lined with a sea pine wooden sheathing of perforated sound-absorbing and lightly pigmented panels.

\section{Challenges}

The fire station is a registered architectural monument, which made the project a planning challenge. Only through close examination of the existing building could the real condition of the building, in parts quite seriously deteriorated, be determined. For example, destructive dry rot growing in the floor beams through the masonry joints between the first and second floors had to be extensively removed.

Due to the historic preservation status, a new staircase could not be created to provide for a second fire escape route for the upper floors of the old six-story 
former hose drying tower. Since the tower could not be put to public use, visitor access was limited to the ground and first floor only. To make use of the areas not accessible to the public, the technical support spaces were located in the unused areas of the existing building instead of underneath the new extension, which would have been costly. For example, the bulky ventilation equipment was integrated in the upper levels of the tower. The spiral funnel shape of the new extension proved to be optimal to ensure low velocity of air movement through the new library up to the heat exchanger and discharge vent installed in the tower.

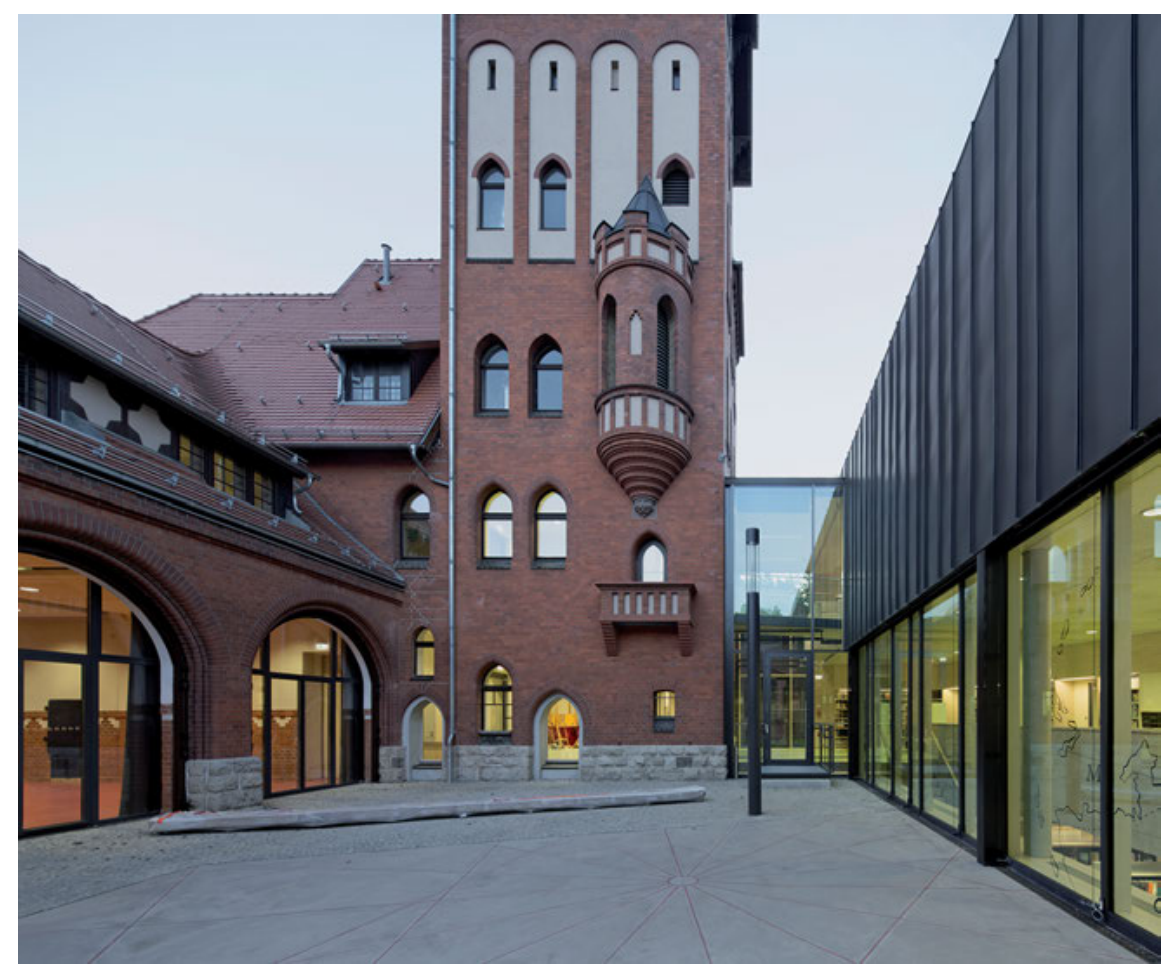

Fig. 10: The library's courtyard with the former hose drying tower and its false architectural elements used for fire brigade practice. (c) Werner Huthmacher.

A surprise was revealed through the investigation of the historic roofing material. During the design, it had been assumed that the dark bitumen shingles used in the GDR renovation of the 1970s, were reminiscent of a historical, black slate roof. However, close study of historic photos and recovered tile shards from the original roof, indicated that the former roof was not slate but rather beaver tail ceramic tiles, stained with a dark colour. However, further studies of the recovered shards 
suggested that the dark colour was perhaps a patina caused by air pollution from the widespread coal heating used at the time. Together with the Office for the Preservation of Monuments, a hygroscopic red beaver tail tile was chosen in the belief that the typical dark patina will, over time, return and unify the concept.

In dealing with the half timber structure of the old building, traditional carpentry methods of the time were used as far as possible including leafed beams, wooden nails and mortise and tenon joints for example. Another surprise was that much of the wooden roof construction was found to be chemically contaminated because wood preservatives had been used in the seventies. Through careful restoration investigation and work methods, it was possible to restore the historic wooden staircase to its original state. During the façade renovation, great care was taken to ensure dirt and damage were removed from the bricks but not the patina. By leaving some of the wear and tear and much of the indications of ageing, it was possible to preserve not only the history of the monument but its dignity as well.

\section{Notes from the Librarians}

In the competition brief, the librarians specified the building requirements. The three areas of the former building, consisting of the main building, engine hall and hose tower, needed to be connected to the new building. An accessible courtyard for outdoor use and the conversion of the fire engine hall into an event room were required. Further general requirements included:

- Professional and operational needs, including RFID technology

- Public use in accordance with legal requirements and individual needs

- Demand-oriented, secure, expandable and innovative IT infrastructure for the entire building

- Individual building services requirements

- Separate planning and construction process for the design of outdoor facilities

- Public art budget integrated into the project (Figure 8)

- Secure financing of the entire project.

The requirements were successfully met by the architects in their design (Radzkowski 2016). The results were:

- Specialist and operational needs: the library occupies the three floors in the new building as well as individual rooms in the hose tower and the engine hall in the old building for public use; the new building, engine hall and 
courtyard can be accessed through the central entrance zone; the roughly 75,000 items in the collection are assigned to specific floors according to use:

- Basement: fiction, audiobooks, film adaptions for adult literature on DVD

- Ground floor: picture books, books for children and adolescents, audiovisual media for adults, children and adolescents and board games

- Upper floor: non-fiction, newspapers and magazines, reference collection.

The architectural office of Chestnutt_Niess was also responsible for the interior architecture which included designing the wall-mounted, integrated shelving, reading tables, service counter, seating and the selection and modification of the free-standing shelves, audiovisual furniture and mobile picture book storage units (Figure 11). The furnishings were made by the company Paul Serafini based in Iserlohn (https://www.serafini.de/home).

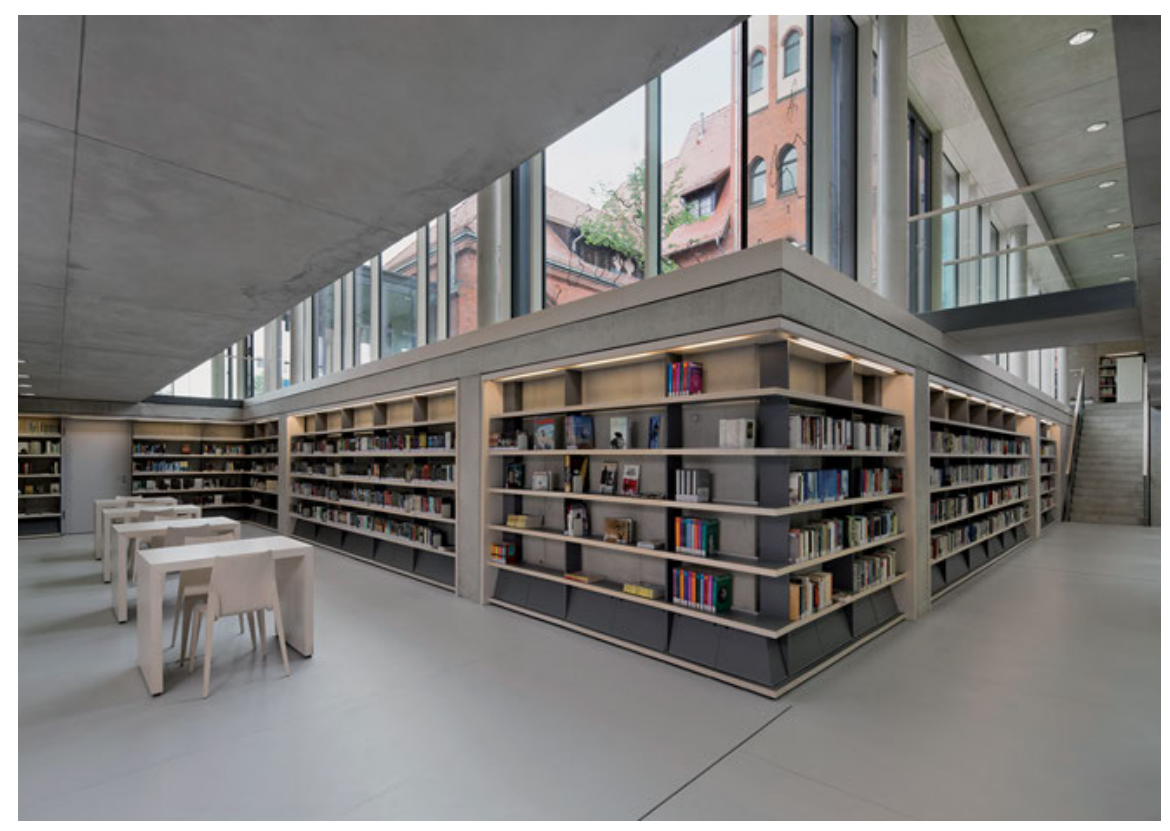

Fig. 11: View from the lower level. () Werner Huthmacher.

Other outcomes were:

- The former engine hall includes event technology, accommodates 80 people and is used for events and projects to promote reading and information literacy, external programmes and courses. 
- Staff workstations are on the upper floor of the engine hall and in the new building together with a conference room and staff toilets. The rooms in the old building can be reached directly via the historic staircase and a bridge between the old and the new building on the upper floor.

- The entire building, old and new, is barrier free. Ramps, floor markings, visual signs and acoustic messages are provided in the staircase and the elevator. On the ground floor of the new building and next to the engine hall, accessible toilets are available. The IT equipment is disabled-friendly.

- RFID technology for self-checkout and collection security are accommodated by three self-service checkout terminals on the ground floor, including one terminal with a cashless payment function, and a security gate next to the counter, which optically and acoustically alerts staff to material not checked out. In the entrance area of the library, two return systems were built into the wall and lead to a sorting system with five bins in a back room, where the container for the external return system can also be found. The system is available $24 / 7$.

- IT infrastructure: The building is connected to the fibre-optic network, which serves all the staff and public desks providing functionality of the RFID equipment and services with associated libraries. Optional connections are available as is free Wi-Fi. The server and network administration are managed at a local and central level.

\section{Conclusion}

The long road to rationalise library services in the city district and merge into a new location has taken time to come to fruition but the impressive result has undoubtedly made the journey worthwhile. A historic landmark building has found appropriate new use and a library service in decline in visitor numbers and uptake of services has seen a revival. A clear sign of the success of the fire station restoration and extension is evidenced daily by the positive reactions of the local population who regularly and enthusiastically use the library.

The architects and librarians have risen to the challenge of combining old and new to create a welcoming, exciting new public library that works well, provides a multiplicity of facilities and is a place the locals want to visit. The character and ambience of the original building have been retained and a new extension, which echoes the architecture of the fire station while making its own clear statement and contribution to the urban cityscape, has been created. Both combine to create an extremely successful award-winning new entity (Architekturpreis 
Berlin 2016). The key requirements of the competition brief including connecting the old and new parts of the building and ensuring a high level of professional services in an IT-rich environment were met, and a range of activities and events can be held in the building. Much more has been achieved (Lieschke 2016). The result is an exciting, contemporary library space retaining the embodied energy and memories of the original building; the old informs the new and a new chapter in the library service has begun.

\section{References}

Architekturpreis Berlin 2016. “Mittelpunktbibliothek Treptow, Umbau und Erweiterung einer denkmalgeschützten Feuerwache.” http://www.architekturpreis-berlin.de/Archiv/2016/ Projekte/074/

Lieschke, Anke. 2016. “Den Ort lesbar machen: Mittelpunktbibliothek Alte Feuerwache in Berlin.” Deutsche Bauzeitung, 149, no.12: 34-39. https://www.db-bauzeitung.de/ $\mathrm{db}$-themen/schwerpunkt/den-ort-lesbar-machen/

Radzkowski, Jürgen. 2016. “Die Feuerwache und die Bibliothek - eine dauerhafte Beziehung." BuB, Forum Bibliothek und Information, 6.9.2016. https://b-u-b.de/feuerwache/ 